\title{
Bioinformatic analysis of glycogen synthase kinase 3: human versus parasite kinases
}

\author{
DMITRY I. OSOLODKIN ${ }^{1}$, NATALIA V. ZAKHAREVICH ${ }^{2}$, \\ VLADIMIR A. PALYULIN ${ }^{1}$, VALERY N. DANILENKO ${ }^{2,3}$ and NIKOLAY S. ZEFIROV ${ }^{1}$ \\ ${ }^{1}$ Department of Chemistry, Moscow State University, Leninskie Gory 1/3, Moscow 119991, Russia \\ ${ }^{2}$ Institute of General Genetics RAS, Gubkin street 3, Moscow 119991, Russia \\ ${ }^{3}$ Research Center for Biotechnology of Antibiotics (BIOAN), Solzhenitsyn Street 27, Moscow 109004, Russia
}

(Received 4 August 2010; revised 2 October, 18 December 2010 and 13 Fanuary 2011; accepted 15 Fanuary 2011; first published online 24 February 2011)

\section{SUMMARY}

Objective. Glycogen synthase kinase 3 (GSK-3) is a promising target for the treatment of various human diseases such as type 2 diabetes, Alzheimer's disease and inflammation. Successful inhibition of the homologues of this kinase in Plasmodium falciparum, Trypanosoma brucei and Leishmania donovani makes the kinase an attractive target for the treatment of malaria, trypanosomiasis and leishmaniasis, respectively. The aim of this work was to compare the binding sites of the GSK-3 kinases of different parasites and to analyse them as possible targets for therapeutic compounds. Methods. Both a sequence alignment and homology models of the structure of 21 different GSK-3 homologues belonging to mammals, insects, pathogenic fungi, nematodes, trematodes and protozoa have been analysed, 17 of them being studied for the first time. Results. The structure of the kinases and, in particular, their binding sites, were found to be rather conserved, possessing small insertions or deletions and conserved amino acid substitutions. Nevertheless, the kinases of most species of parasite did have some amino acid differences from the human kinase, which could be exploited for the design of selective drugs. Conclusion. Comparison of the human and parasite GSK-3 ATP binding site models has shown that the development of selective drugs affecting parasite GSK-3 is possible. Known inhibitors of human GSK-3 can also be used as starting scaffolds for the search for drugs acting against parasitic diseases.

Key words: glycogen synthase kinase 3, GSK-3, bioinformatics, molecular modelling, Wnt pathway, neglected diseases, malaria, schistosomiasis, leishmaniasis, trypanosomiasis, filariasis.

\section{INTRODUCTION}

Parasitic diseases are a serious health problem, especially in developing countries. Virtually all people are threatened to some extent by eukaryotic parasites of different species, so the design of new effective anti-parasite drugs is a task of outstanding importance. Additional difficulties emerge due to the parasites' rapid development of resistance and therefore novel drugs affecting previously unexplored targets are needed. Among these targets, protein kinases are very promising due to the existing knowledge base accumulated during studies of human kinases. Extensive target analysis is needed before planning experimental work.

Design of new kinase inhibitors is a widely studied problem in drug discovery, and interest in various kinases as drug targets is growing. Such inhibitors are most widely studied in the context of cancer treatment (Zhang et al. 2009a), but new applications of this approach regularly emerge, including

* Corresponding author: Department of Chemistry, Moscow State University, Leninskie Gory 1/3, Moscow 119991, Russia. Tel: +74959393969. Fax: +749593902 90. E-mail:vap@qsar.chem.msu.ru anti-bacterial (Kurosu and Begari, 2010), antiprotozoal (Canduri et al. 2007) and anti-parasitic (Liotta and Siekierka, 2010) drug development. Nevertheless, the potential of many parasite kinases for therapeutic intervention has not been studied thoroughly.

Glycogen synthase kinase $3(\mathrm{GSK}-3)$ is a conserved eukaryotic enzyme participating in different cellular pathways. The first identified function of the kinase was phosphorylation of glycogen synthase in rabbit skeletal muscle (Embi et al. 1980), and a number of different targets were then found for this kinase in the human organism (Rayasam et al. 2009). Inhibition of GSK-3 can be used during the treatment of Alzheimer's disease (Avila et al. 2010), type 2 diabetes (Henriksen and Dokken, 2006), shock and inflammation (Dugo et al. 2007). One of the most important functions of GSK-3 inhibition is the regulation of the cellular signalling pathway Wnt, which leads to the stabilization of $\beta$-catenin and gene expression (Wu and Pan, 2009). Despite the activation of this pathway in many cancer conditions, systemic pharmacological inhibition of GSK-3 does not lead to carcinogenesis in healthy subjects (Patel and Woodgett, 2008) and may even have anti-cancer effects due to inhibition of the insulin pathway that is 


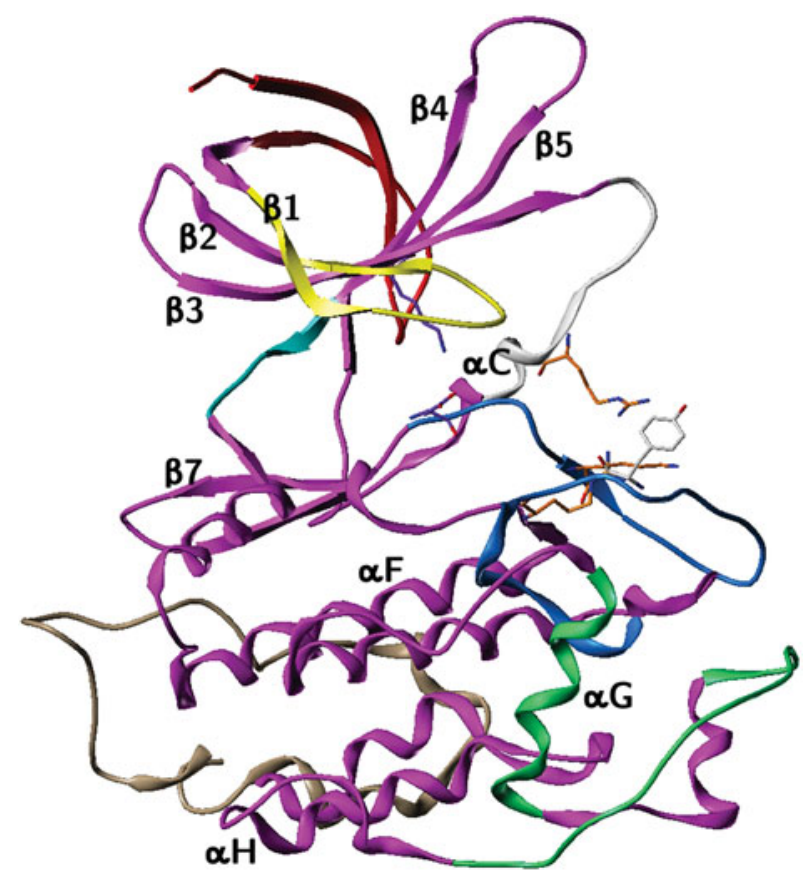

Fig. 1. Structure of human GSK-3 $\beta$ residues 35-383 (PDB ID 1UV5 (Meijer et al. 2003)). Cartoon representation is coded by colours: N-terminal region (up to residue 55) - red; non-specific parts of the kinase domain (residues 56-340) - magenta; glycine loop-yellow; loop and helix $\mathrm{C}$ - white; hinge-cyan; activation loop - blue; axin-binding site - greenblue; C-terminal region (residues 341-383) - tan. Conserved residues are purple (Lys85 and Asp200 - common for all kinases), orange (Arg96, Arg180, Lys 205-priming phosphate-binding site) and white

(Tyr216-phosphorylation site at activation loop).

activated in certain types of cancer (Ougolkov and Billadeau, 2006). There is much evidence that at least 2 independent pools of GSK-3 exist in cells (Frame and Zheleva, 2006), one being involved in the Wnt pathway and another one regulated by Akt/PKB in the glycogen metabolism pathway.

Although GSK-3 possesses the common kinase fold (Fig. 1) and function, it has a number of specific features. The kinase shows a strong preference for pre-phosphorylated (primed) substrates bearing a phosphate group in position $(N+4)$, where $N$ is the number of the residue phosphorylated by GSK-3. The kinase is constitutively active and is usually regulated by autoinhibition following the Akt/PKBmediated phosphorylation of Ser21 (GSK-3 $\alpha$ ) or Ser9 (GSK-3 $\beta$ ) which occupies the priming phosphate binding site and prevents substrate binding (Dajani et al. 2001). The kinase is activated by Tyr216 (residue numbering is according to human GSK-3 $\beta$ sequence if not stated otherwise) autophosphorylation shortly after expression, but this effect is unidirectional, and activity of the kinase is not regulated by the reversible phosphorylation of this residue (Lochhead et al. 2006). Another route of GSK-3 inhibition is phosphorylation of Ser389 by p38 MAP kinase (Thornton et al. 2008).
Two isoforms of GSK-3, $\alpha$ and $\beta$, are present in the human organism along with GSK-3 $\beta 2$, a splice variant of the $\beta$-isoform (Rayasam et al. 2009). The difference between isoforms is subtle in the catalytic domain and more pronounced in the $\mathrm{N}$-terminal region, where the $\alpha$-isoform has a large glycine-rich insertion. The isoforms possess different expression profiles and biological function (Liang and Chuang, 2006), but creation of selective ATP-competitive inhibitors for them is hardly possible due to the identity of the ATP binding sites. Different organisms also possess more than one GSK-3 isoform: for example, 4 homologues of GSK-3 were identified in Saccharomyces cerevisiae (Kassir et al. 2006), and at least 15 isoforms are known for SHAGGY, a GSK-3 homologue from Drosophila melanogaster (Hoskins et al. 2007).

Glycogen synthase kinase 3 is a validated target for anti-protozoal drugs. It was shown that inhibitors of GSK-3 can be used against Plasmodium falciparum (Droucheau et al. 2004), Leishmania donovani (Xingi et al. 2009), Toxoplasma gondii (Qin et al. 1998) and Trypanosoma brucei (Ojo et al. 2008); however, only well-known inhibitors of the human kinase were tested in these trials. Recently, a number of antimalarial compounds were identified which inhibit the growth of $P$. falciparum, and many of them are known to inhibit human GSK-3 (Gamo et al. 2010). Inhibition of GSK-3 was also studied during embryogenesis of ticks (Rhipicephalus (Boophilus) microplus) and was suggested as a possible tactic for tick control (Logullo et al. 2009; Fabres et al. 2010).

Homology modelling has previously been performed for protozoal kinases (Droucheau et al. 2004; Ojo et al. 2008; Xingi et al. 2009) with the aim of proposing the inhibitor binding mode. A P. falciparum GSK-3 model was also extensively analysed by Kruggel and Lemcke (2009a,b). Xiao et al. (2004) performed a homology modelling and molecular dynamics study of Arabidopsis thaliana GSK-3/ SHAGGY-like kinase, but that study is of limited relevance to the design of new anti-parasitic drugs. A direct comparison of GSK-3 models for various organisms, especially parasitic worms and fungi, and thorough sequence analysis has never been performed.

The main aim of this study was to analyse the possible application of GSK-3 inhibitors as selective anti-parasitic drugs. We have considered the selectivity issues based on amino acid composition of the ATP binding site and constructed molecular models of parasite GSK-3 enzymes.

\section{MATERIALS AND METHODS}

\section{Sequence analysis and alignment}

The amino acid sequences of the proteins under consideration (Table 1) were obtained from the PubMed Protein database. Catalytic domains were 
Table 1. GSK-3 sequences considered in this study

\begin{tabular}{|c|c|c|c|c|c|}
\hline Access code & Name & Organism & Length & $\begin{array}{l}\text { Kinase domain } \\
\text { identity with } \\
\text { HsGSK- } 3 \beta\end{array}$ & $\begin{array}{l}\text { Kinase domain } \\
\text { similarity to } \\
\text { HsGSK- } 3 \beta\end{array}$ \\
\hline P49840.2 & HsGSK-3 $\alpha$ & Homo sapiens & 285 & $89 \%$ & $95 \%$ \\
\hline Q6FI27 & HsGSK- $3 \beta$ & Homo sapiens & 292 & $100 \%$ & $100 \%$ \\
\hline Q2NL51.2 & MmGSK-3 $\alpha$ & Mus musculus & 286 & $88 \%$ & $94 \%$ \\
\hline Q9WV60.2 & MmGSK-3 $\beta$ & Mus musculus & 292 & $100 \%$ & $100 \%$ \\
\hline P18265.1 & RnGSK-3 $\alpha$ & Rattus norvegicus & 285 & $89 \%$ & $94 \%$ \\
\hline P18266.1 & $\mathrm{RnGSK}-3 \beta$ & Rattus norvegicus & 292 & $99 \%$ & $100 \%$ \\
\hline NP_001121915.1 & SsGSK $-3 \beta$ & Sus scrofa & 292 & $99 \%$ & $99 \%$ \\
\hline ABO 61882.1 & RmGSK-3 & Rhipicephalus microplus & 285 & $84 \%$ & $93 \%$ \\
\hline Q1HRP9 & $\mathrm{AaGSK}-3$ & Aedes aegypti & 285 & $83 \%$ & $93 \%$ \\
\hline AAN09082.1 & SHAGGY & Drosophila melanogaster & 285 & $83 \%$ & $93 \%$ \\
\hline XP_001897721.1 & BmGSK-3 & Brugia malayi & 277 & $66 \%$ & $75 \%$ \\
\hline XP_002572305.1 & SmGSK-3 & Schistosoma mansoni & 285 & $77 \%$ & $88 \%$ \\
\hline EEQ85886.1 & AdGSK-3 & Ajellomyces dermatitidis & 284 & $72 \%$ & $84 \%$ \\
\hline EEH21342.1 & PbrGSK-3 & Paracoccidioides brasiliensis & 284 & $71 \%$ & $83 \%$ \\
\hline Q0CKX1 & AtGSK-3 & Aspergillus terreus & 268 & $68 \%$ & $77 \%$ \\
\hline AFUA_6G05120 & AfGSK-3 & Aspergillus fumigatus Af293 & 284 & $72 \%$ & $83 \%$ \\
\hline CHGG_07166 & CgGSK-3 & Chaetomium globosum CBS 148.51 & 284 & $71 \%$ & $81 \%$ \\
\hline CNB007 20 & CnGSK-3 & Cryptococcus neoformans & 332 & $66 \%$ & $75 \%$ \\
\hline XP_002418374.1 & CdGSK-3 & Candida dubliniensis & 283 & $59 \%$ & $79 \%$ \\
\hline CIMG_02613 & CiGSK-3 & Coccidioides immitis $R S$ & 284 & $71 \%$ & $83 \%$ \\
\hline O77344 & PfGSK-3 & Plasmodium falciparum 3D7 & 287 & $56 \%$ & $75 \%$ \\
\hline Q4Z6R7 & PbGSK-3 & Plasmodium berghei & 287 & $55 \%$ & $73 \%$ \\
\hline CAM67080.1 & LiGSK-3 & Leishmania infantum & 330 & $44 \%$ & $63 \%$ \\
\hline 3E3P_B & LmGSK-3 & Leishmania major & 330 & $44 \%$ & $63 \%$ \\
\hline ABR18737.1 & LdGSK-3 & Leishmania donovani & 330 & $44 \%$ & $63 \%$ \\
\hline Q0PKV3 & LmxGSK-3 & Leishmania mexicana & 330 & $44 \%$ & $63 \%$ \\
\hline XP_001563953.1 & LbGSK-3 & Leishmania braziliensis & 327 & $45 \%$ & $63 \%$ \\
\hline P49841 & TbGSK-3 & Trypanosoma brucei & 327 & $47 \%$ & $64 \%$ \\
\hline AF042826 & TPK3 & Toxoplasma gondii & 298 & $54 \%$ & $73 \%$ \\
\hline
\end{tabular}

extracted according to annotation where possible, and in other cases were assigned by homology. Alignment of amino acid sequences (Fig. 2) was performed with ClustalX 2.0.11 (Larkin et al. 2007), manual adjustments were introduced where needed. Sequence identity was calculated with GENEDOC (Nicholas et al. 1997). A phylogenetic tree was built using the MEGA 4 program ('Tamura et al. 2007) with the following parameters: Analysis-phylogeny reconstruction, Method-Neighbour-joining, Bootstrap - 1000 replicates, Model-p-distance.

\section{Molecular modelling}

The modelling of protein structures was performed with Modeller 9v7 (Šali and Blundell, 1993). The $\mathrm{X}$-ray structures of human GSK- $3 \beta$ complexed with indirubin inhibitors (PDB access codes 1UV5 (Meijer et al. 2003) and 1Q41, chain B (Bertrand et al. 2003)) were used as the templates for modelling, as it has been shown in previous studies that indirubins are equipotent inhibitors of the parasite and human kinases. For each target, 50 models were generated based on each template and optimized by Modeller's internal simulated annealing procedure (slow optimization of the model, 300 iterations of the conjugate gradient runs, very slow simulated annealing refinement, 3 repeats of the optimization cycle until objective function was $>10^{6}$ ). The best model was selected according to the DOPE score and objective function implemented in Modeller and the Procheck validation score (Laskowski et al. 1993), then models built based on each template were compared by Ramachandran plot parameters (Supplementary Table 1; Online version only). Interestingly, in all cases the best ranked model by all criteria was the same. Models based on the 1Q41 template gave better Ramachandran plot parameters consistently, so they were used for further consideration. Folding quality assessed with ProSA z-score (Sippl, 1993) was good for all models (Supplementary Table 1; Online version only). Comparison of the models was performed in SYBYL 8.0 ('Tripos Inc., 1699 South Hanley Road, St Louis, Missouri, 63144, USA).

\section{RESULTS}

\section{Amino acid sequence alignment and phylogeny}

An alignment of amino acid sequences of glycogen synthase kinase homologues belonging to various species of mammals, insects, worms, fungi and protozoa was built (Fig. 2). Mammals and drosophila were used as references, and other organisms are either pathogenic or serve as transmitters of different diseases (e.g. A. aegypti or R. microplus). The sequence 

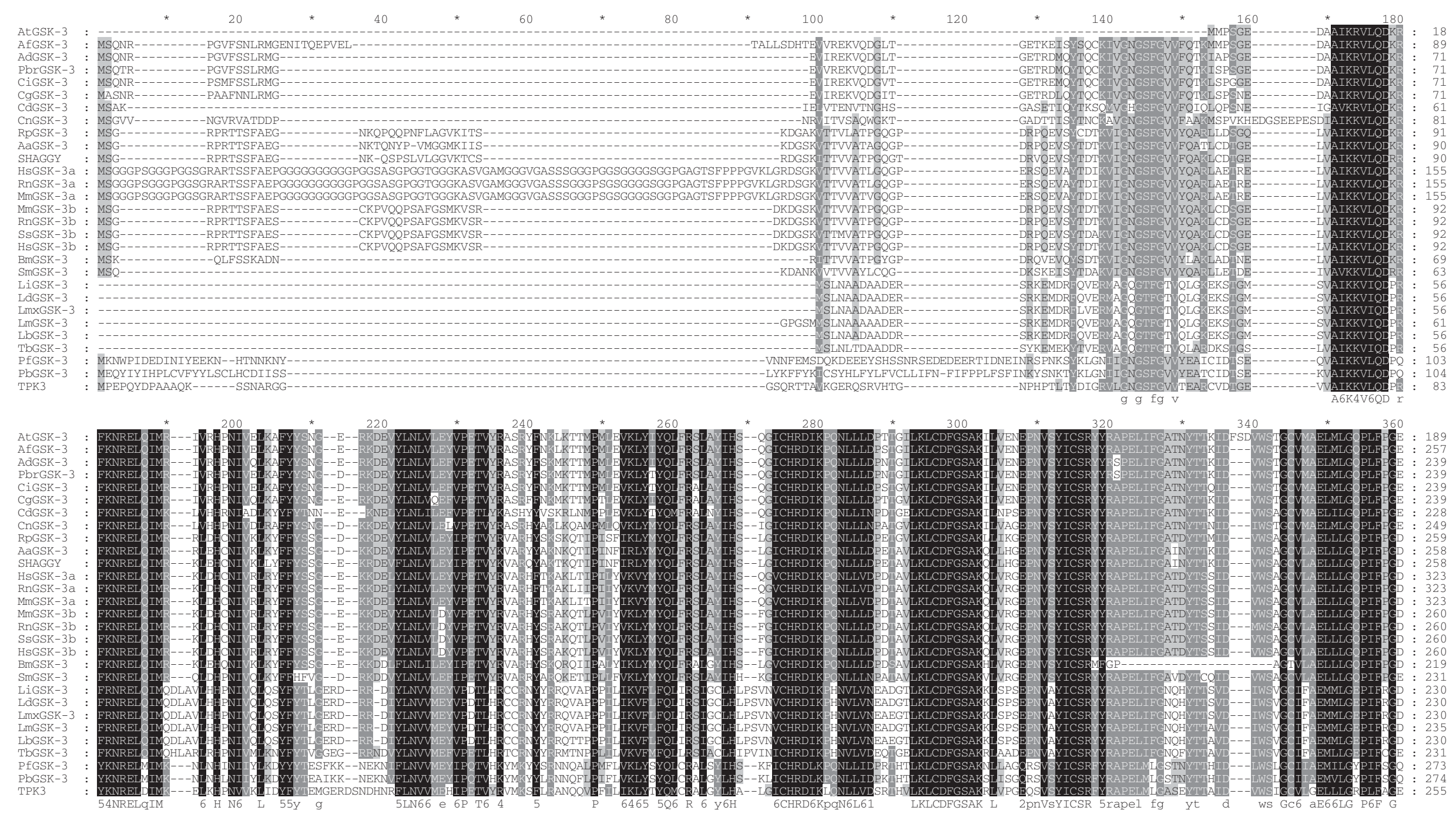

Fig. 2. (Cont.) 
Table 2. Insertions and deletions in the catalytic domains of studied kinases relative to the human GSK-3 (see Fig. 3)

\begin{tabular}{|c|c|c|}
\hline Group & Kinases & Differences \\
\hline I & $\begin{array}{l}\text { Hs } \alpha, \operatorname{Hs} \beta \\
\operatorname{Rn} \alpha, \operatorname{Rn} \beta \\
\text { Mm } \beta, \mathrm{Ss} \\
\text { Shaggy, } \\
\text { Rm, Aa, } \\
\text { Sm }\end{array}$ & None \\
\hline Ia & $\operatorname{Mm} \alpha$ & $\begin{array}{l}1 \text { residue inserted } \mathrm{N} \text {-terminal to } \\
\mathrm{H} \text { helix }\end{array}$ \\
\hline II & $\begin{array}{l}\text { Lm, Li, } \\
\text { Ld, Lmx, } \\
\text { Lb }\end{array}$ & $\begin{array}{l}3 \text { residues inserted at loop } \beta 4-\beta 5 \text {, } \\
1 \text { residue } \mathrm{C} \text {-terminal to helix } \mathrm{C} \text {, } \\
2 \text { residues in the loop } \alpha \mathrm{F}-\beta 7 \text {, and } \\
3 \text { residues } \mathrm{N} \text {-terminal to } \mathrm{H} \text { helix }\end{array}$ \\
\hline III & $\mathrm{Cn}$ & 9 residues inserted at loop $\beta 2-\beta 3$ \\
\hline IV & ТPК3 & $\begin{array}{l}4 \text { residues inserted at loop } \beta 4-\beta 5 \\
\text { and } 9 \text { residues } \mathrm{N} \text {-terminal } \\
\text { to } \mathrm{H} \text { helix }\end{array}$ \\
\hline $\mathrm{V}$ & $\mathrm{Bm}$ & $\begin{array}{l}\text { fragment deleted between the } \\
\text { activation loop and helix } F \\
\text { (residues 221-241) and large loop } \\
\text { forming the axin binding site } \\
\text { (residues 278-298) }\end{array}$ \\
\hline VI & $\mathrm{Tb}$ & $\begin{array}{l}2 \text { residues inserted } \mathrm{C} \text {-terminal to } \\
\text { helix } \mathrm{C} \text { and } 2 \text { residues in the loop } \\
\alpha \mathrm{F}-\beta 7\end{array}$ \\
\hline VII & $\mathrm{Pf}, \mathrm{Pb}$ & 2 residues inserted at loop $\beta 4-\beta 5$ \\
\hline VIII & $\begin{array}{l}\mathrm{Ad}, \mathrm{Af} \\
\mathrm{Pbr} \\
\mathrm{Ci}, \mathrm{Cg}\end{array}$ & $\begin{array}{l}1 \text { residue deleted } \mathrm{N} \text {-terminal to } \\
\mathrm{H} \text { helix }\end{array}$ \\
\hline VIIIa & $\mathrm{Cd}$ & $\begin{array}{l}1 \text { residue deleted } N \text {-terminal to } H \\
\text { helix and } 1 \text { residue at loop } \beta 4-\beta 5\end{array}$ \\
\hline VIIIb & At & $\begin{array}{l}1 \text { residue deleted N-terminal to } \mathrm{H} \\
\text { helix and glycine loop ( } \beta 1 \text { and } \beta 2 \\
\text { strands), } 3 \text { residues inserted in the } \\
\text { loop } \alpha \mathrm{F}-\beta 7\end{array}$ \\
\hline
\end{tabular}

identity of catalytic domains was significant, the least similar to human GSK-3 $\beta$ being leishmanial kinases possessing $44 \%$ identity. The conserved regions and residues correspond to the standard GSK-3 catalytic domain; insertions and deletions are located mainly in the loop regions and do not affect the ATP-binding region, activation loop and priming site. The most notable exceptions are AtGSK-3 lacking the glycine loop (probably due to errors in genome annotation), and BmGSK-3 possessing the large deletions in the region between the activation loop and $\mathrm{C}$-terminus that corresponds to the axin binding site; interestingly, the C-terminal region of BmGSK-3 is highly homologous to the respective part of HsGSK-3.

In most cases auto-inhibition of the kinase by the phosphorylated N-terminal domain is possible: these domains are long enough to interact with the priming phosphate binding site. Nevertheless, certain organisms such as leishmania or trypanosoma lack the $\mathrm{N}$-terminal domain and consequently may not have this option. Worms and the majority of fungi have a rather short $\mathrm{N}$-terminal sequence containing a putative phosphorylatable serine residue (e. g., Ser2, Ser10 and Ser11 of PbrGSK-3).

$\mathrm{C}$-terminal domains of the studied kinases are of similar size. SHAGGY has the longest C-terminal domain, leishmanial and trypanosomial kinases lack the non-conserved part of the domain. Data on the function of this domain are scarce, and its further consideration would be overly speculative.

Many functionally important residues are conserved throughout the studied kinases. Apart from Lys85, Asn186, Asp200, and other residues crucial for kinase function which are characteristic for the whole protein kinase superfamily, residues forming the priming phosphate binding site (Arg96, Arg180, Lys205), affecting substrate binding (Phe67) and interacting with Tyr216 (Arg 220 and Arg223) are also present in all studied sequences. Certain residues lining the ATP-binding pocket are also identical for all GSK-3s: Gly63, Val70, Ala83, Pro136, Thr138, Leu188, and Cys199. The variable residues are described along with the models (see next section).

A phylogenetic tree of the GSK-3s corresponds to the phylogeny of the studied species (Supplementary Fig. 1; Online version only). Protozoal kinases form a distinct branch, and another branch is formed by metazoa. Fungal kinases comprise a separate branch from animal kinases. Mammalian kinases form 2 distinct groups corresponding to the $\alpha$ and $\beta$ isoforms, other branches are formed by insect and worm kinases. Protozoa are characterized by the greatest diversity and distance from human kinases; for example, the distance between the plasmodial and leishmanial sequences is much larger than the distance between the human and insect kinases.

\section{Modelling of the catalytic domains of the kinases}

Overall characterization of the models. All models built possess good stereochemical quality. According to PROCHECK, no more than $2 \%$ of residues are located in the disallowed and generously allowed regions of the Ramachandran plot for each model that corresponds to the overall quality of the models. Due to significant similarity between the template and target sequences, root-mean-square deviation (rmsd) of the $\mathrm{C}_{\alpha}$ atoms between the template and models is low and does not exceed $2 \cdot 1 \AA$ for any model except the model of TPK3 (rmsd 5.84 A) (Fig. 3). The high rmsd of the latter model is due to the presence of the large insertions leading to the overall displacement of the backbone compared to the template.

The sequence length of the catalytic domain of mammalian and insect kinases is the same, except MmGSK-3 $\alpha$, which bears a single insertion $\mathrm{N}$-terminal to $\mathrm{H}$ helix (Table 2). Insertions or deletions (indels) at this site are most abundant among studied kinases, but they are of no use for targeting selective inhibitors because this loop does not affect the enzyme function. The second site of 


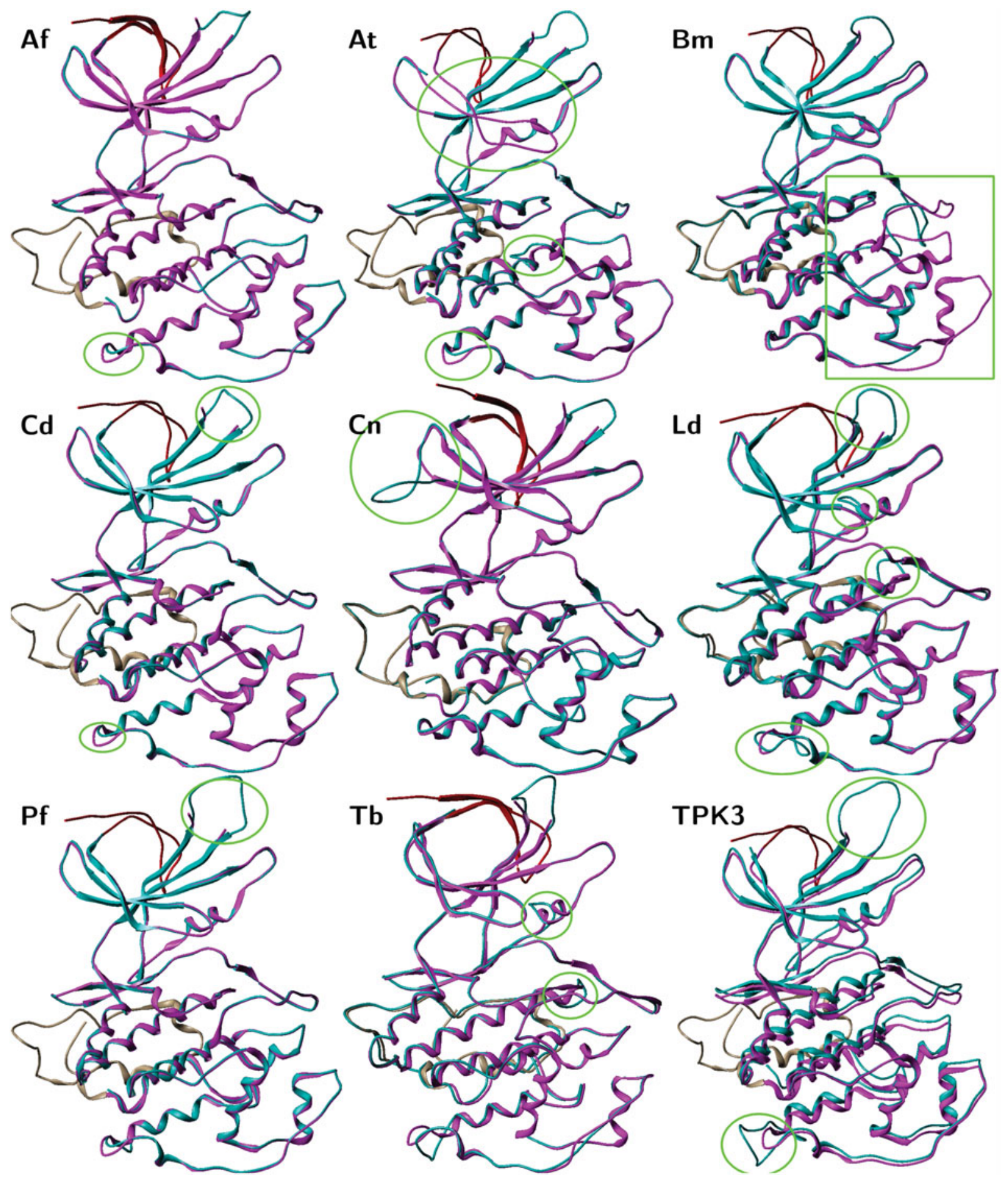

Fig. 3. Location of the insertions and deletions in the modelled kinases (coloured cyan) compared with the human GSK-3 $\beta$ (PDB access code 1Q41; coloured red, magenta and tan).

frequent indels is located at the flexible loop $\beta 4-\beta 5$, which also cannot be used for inhibitor design.

Insertions at the $\mathrm{C}$ helix observed in the leishmanial and trypanosomial kinases are more interesting since they can lead to substantial change of the kinase conformation near the binding site of noncompetitive inhibitors (Martinez et al. 2005; Ibrahim et al. 2008; Peng et al. 2010). A similar effect may occur due to the presence of insertions at the $\alpha \mathrm{F}-\beta 7$ loop, which are present in leishmanial kinases. Taken together, these differences near the phosphatebinding site may be explored in the design of new non-competitive inhibitors.

GSK-3 of $C$. neoformans has a unique large insertion in the $\beta 2-\beta 3$ loop, which can probably interact with the hinge region or change the flexibility of the glycine loop. As opposed to the other fungal kinases, this one does not have any deletions in the $\mathrm{H}$ helix region. Nevertheless, binding sites of the fungal kinases resemble each other closely (vide infra). The 
Table 3. Frequency of appearance of certain residues in the binding site (\%) and gene conservation scores

(Human residues are marked in bold.)

\begin{tabular}{|c|c|c|c|c|c|c|c|c|c|c|c|c|c|c|}
\hline Position & A & $\mathrm{D}$ & $\mathrm{E}$ & $\mathrm{F}$ & $\mathrm{H}$ & I & $\mathrm{K}$ & $\mathrm{L}$ & $\mathrm{M}$ & $\mathrm{Q}$ & $\mathrm{R}$ & V & $\mathrm{Y}$ & Score \\
\hline 62 & 21 & & & & & 50 & & 4 & & & & 25 & & 6 \\
\hline 110 & 3 & & & & & 7 & & & & & & 90 & & 8 \\
\hline 132 & & & & & & & & 66 & 31 & 3 & & & & 7 \\
\hline 134 & & & & 21 & 3 & & & 3 & & & & & 72 & 1 \\
\hline 135 & & & & & & 28 & & & & & & 72 & & 7 \\
\hline 137 & & 17 & 76 & & & & & & & 7 & & & & 7 \\
\hline 141 & & & & & & & 17 & & & & 83 & & & 6 \\
\hline 185 & & & & & 21 & & & & & 79 & & & & 9 \\
\hline
\end{tabular}

only exception is A.terreus GSK-3, which lacks the glycine loop forming the 'ceiling' of the binding site. Such a deletion should be non-functional due to the importance of the glycine loop for kinase activity and interaction with the substrate (Zhang et al. 2009b). Consequently, its presence could be explained by a gene sequencing or annotation inaccuracy.

B. malayi has a unique GSK-3 structure which lacks 2 large regions present in the other kinases under consideration. Firstly, residues 278-298, which form the outer wall of the axin binding site, are deleted (Dajani et al. 2003). Secondly, a large deletion occurs between the activation loop and F helix. Nevertheless, the deletions do not affect the priming phosphate-binding site, Tyr216 and the ATP-binding site. Whilst seemingly not affecting the enzymatic function of GSK-3, they should, however, change the substrate selectivity profile of the kinase. Interestingly, helix $\mathrm{G}$ is conserved in BmGSK-3 and still can serve as a site of axin interaction despite the deletion of other axin-binding elements.

ATP-binding pocket. Despite the high similarity between the models, certain differences between the species do exist in the ATP-binding pocket that may affect the profile of the inhibitor selectivity. There are 8 such residues (Fig. 4): Ile62 (Val, Ala, Leu), Val110 (Ile, Ala), gatekeeper Leu132 (Met, Gln), Tyr134 (Phe, His, Leu), Val135 (Ile), Glu137 (Gln, Asp), Arg141 (Lys), and Gln185 (His). The conservation of gene sequence varies for these substitutions from very good (Gln185) to poor (Tyr134); conservation scores for variable residues as computed with ConSurf3.0 (Glaser et al. 2003; Landau et al. 2005; Ashkenazy et al. 2010) are given in Table 3.

The residues of the ATP-binding pocket differ in their importance to inhibitor binding. For example, inhibitors can interact only with the backbone of Asp133, and mutations in this position should not affect inhibitor binding. A similar situation is observed for Tyr134: there are no inhibitors for which an interaction with the side-chain hydroxyl group has been shown, although such an interaction can appear in docking solutions (D. I. Osolodkin unpublished observation).
The binding pockets of insect and worm kinases are similar to those of mammalian kinases. The substitution Val135Ile appears in all studied cases and Arg141Lys is found in AaGSK-3 and SHAGGY. The former substitution does not change the physical properties of the binding site, but leads to a small decrease of the binding site volume. The latter substitution is functionally conserved: the Lys residue can form the same salt bridge with Glu137 as Arg, although the lysine residue is less conformationally restricted than arginine. SmGSK-3 also has a Tyr134Phe substitution, but its influence on inhibitor selectivity is minimal.

All fungal kinases have a valine residue instead of Ile62 that leads to easier entrance of ligands into the binding pocket due to its smaller volume. Most of them also have a Tyr134Phe substitution, and 2 species possess unique substitutions strongly affecting the selectivity of inhibitors: Val110Ala along with Ile62Val in CdGSK-3 opens the possibility of accepting significantly larger molecules than the human kinase does, and CgGSK-3 has a rare (Zuccotto et al. 2010) glutamine residue in the gatekeeper position, the presence of which can be exploited in the design of selective inhibitors forming a hydrogen bond with the amide group.

The binding sites of protozoal kinases are the most diverged and the most diverse. The main difference between the human and protozoal GSK-3s is the substitution of the gatekeeper residue Leu132Met, which affects the volume of the binding site. Position 62 may be occupied by alanine (leishmania and trypanosoma), leucine (toxoplasma), or isoleucine (plasmodium). Plasmodium also has Ile residues in positions 110 and 135 . The salt bridge between Arg141 and the residue in the position 137 (Glu or Asp) is possible in all cases except plasmodium, which possesses a Gln residue in position 137 and a Lys residue in the position 141. Nevertheless, leishmanial kinases lack this salt bridge due to the greater distance between Arg and Asp compared to Glu. Position 185 differs in leishmanial and trypanosomial kinases from the others: a histidine residue is present instead of glutamine. 


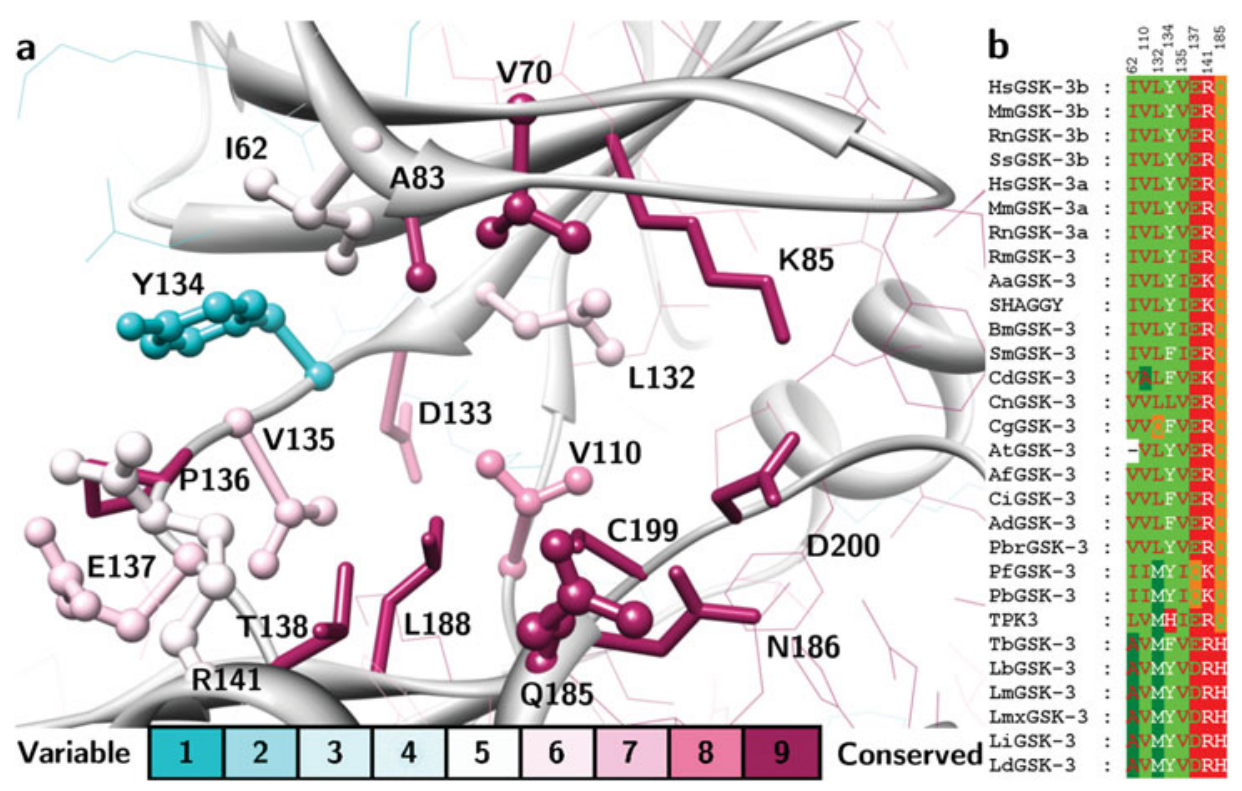

Fig. 4. (a) Conservation of the ATP-binding pocket. Absolutely conserved residues and Asp133 are shown as sticks, variable residues - as balls-and-sticks. Colouring scheme is according to the conservation score (Table 3). (b) Variable residues of the binding pocket and neighbouring regions in the kinases under consideration. Colouring is according to the chemical properties of the residues (red on green-bulky lypophilic, red on dark green-small lypophilic, white on green-aromatic, green on red-acidic, white on red-basic, white on dark green-sulfur-containing, green on orange-amide-containing).

\section{DISCUSSION}

Glycogen synthase kinase 3 is a functionally conserved enzyme among eukaryotes, whose 2 main functions are glucose metabolism and regulation of cell development and cell fate (Kassir et al. 2006). Variability of the sequence is rather low and is mostly localized outside the core regions of the catalytic domain (Fig. 5). Specific features of this domain such as the priming phosphate-recognition site, phosphorylation site in the activation loop (Tyr216), and arginine residues which interact with the phosphorylated Tyr216, are present in all sequences.

Slight differences are observed in the ATP binding pockets of the modelled kinases. They do not seem to be crucial enough to define strict criteria of inhibitor selectivity, but are sufficient to achieve 10 - to 30 -fold selectivity of certain inhibitors between the human and parasite kinases (Droucheau et al. 2004; Ojo et al. 2008; Xingi et al. 2009). Paullones and indirubins are the most widely studied classes of GSK-3 inhibitors. Whereas indirubins are non-selective inhibitors and possess high affinity both to human and protozoal kinases, paullones bind 10- to 1000-fold tighter to human kinases than to protozoal. With the help of our models, it is possible to explain this fact. Firstly, paullones form only 2 hydrogen bonds with the hinge backbone, whereas indirubins form 3 (Bertrand et al. 2003), and this interaction is more favourable. Secondly, the methionine gatekeeper is longer and more flexible than the leucine one and can lead to steric complications during paullone binding (Kruggel and Lemcke, 2009a). Additional steric clashes in the binding-site entrance may be introduced in plasmodial

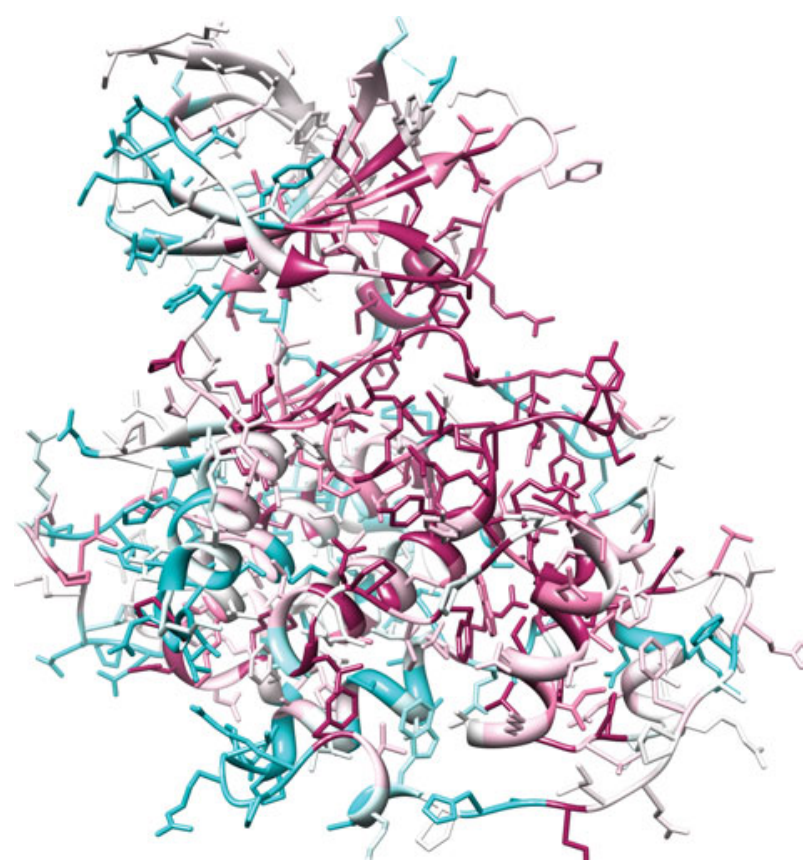

Fig. 5. Overall conservation of GSK-3 sequence. Orientation of the protein is the same as in Fig. 1. Colour legend as in Fig. 4.

kinases by the Lys141 residue that is not restrained by a salt bridge and, moreover, can interact with the backbone carbonyl of residue 62 in a similar fashion to cyclin-dependent kinase 2 (Bhat et al. 2003). A similar situation can evolve in leishmanial kinases, which lack the salt bridge between Arg141 and Asp137 due to the shortness of the Asp side chain. Finally, the presence of 2 isoleucine residues instead of valines decreases the 
volume of the binding site and allows the acceptance of smaller inhibitors.

Fungal and worm glycogen synthase kinases 3 are more similar to human than to protozoal equivalents. The effects of their inhibition were not studied experimentally, but it is likely that GSK-3 also participates in pathways analogous to mammals and insects, for example, in glycogen metabolism or the Wnt pathway. Inhibition of GSK-3 leads to the failure of these pathways and should be lethal for simple organisms such as worms or fungi. Thus, new selective GSK-3 inhibitors could be used for treatment of fungal infections, schistosomosis and filariasis. Inhibitors of HsGSK-3 may be used as the starting scaffolds for the design of such inhibitors. Nevertheless, one should not exclude the possibility of preferential activation of Wnt pathway in special circumstances and subsequent activation of parasite growth.

Binding sites of the worm kinases contain only 1 significant substitution, Val135Ile, which leads to the slight decrease of the binding-site volume. Consequently, certain inhibitors of HsGSK-3 cannot inhibit worm kinases, but inhibitors of worm kinases could be able to inhibit the human enzyme.

The volume of the fungal kinases' binding site is larger than the volume of the HsGSK-3 binding site, and inhibitors of HsGSK-3 should also inhibit fungal ones. This could be a serious problem if the Wnt pathway is activated upon systemic GSK-3 inhibition due to the potentially rapid development of such fungal infections as candidosis during the treatment of type 2 diabetes (Chellan et al. 2010). On the other hand, the development of selective inhibitors for certain fungi species or strains is possible due to the presence of specific substitutions. Further studies of the GSK-3 inhibitors' influence on fungi growth are needed to clarify this issue.

Certain guidelines for the design of selective GSK-3 inhibitors may be suggested based on our analysis. First of all, one should consider targeting the gatekeeper residue: compounds forming hydrogen bonds with the methionine sulphur atom should be selective for protozoal kinases over the human enzyme bearing the leucine gatekeeper. Highly selective inhibitors may be designed against CgGSK-3 targeting both the specific glutamine gatekeeper and larger binding pocket; other fungal kinases should accept inhibitors with larger hydrophobic substituents than the human kinase can accept. On the other hand, worm kinases may be selectively inhibited by smaller molecules than the human kinase inhibitors. Proper optimization of inhibitor shape is needed to achieve selectivity in this case.

\section{CONCLUSIONS}

We have performed the first direct comparison of the molecular models of glycogen synthase kinase- 3 orthologues belonging to 21 parasitic organisms with human GSK-3. Despite the relatively high similarity between the ATP-binding pockets of human and non-human kinases revealed during this study, there are also certain differences sufficient to design selective inhibitors of parasite kinases. Inhibitors of the human kinase can also be used to treat parasites; at least, these inhibitors may be used as valuable starting points for rational design of novel anti-parasitic drugs.

\section{ACKNOWLEDGEMENTS}

The authors are thankful to Olga Bekker, Boris Nikashin, Liubov Kozlovskaya and Richard Claes for useful comments and suggestions.

\section{FINANCIAL SUPPORT}

This work was supported by the Russian Foundation for Basic Research (D. I. O. and V. A. P., grant number 08-0300783), The Ministry of Education and Science of Russian Federation (D. I. O. and V. A. P., project number P-714), and by the RAS Presidium Program «From Fundamental Sciences to Medicine» (N. V. Z. and V. N. D.).

\section{REFERENCES}

Ashkenazy, H., Erez, E., Martz, E., Pupko, T. and Ben-Tal, N. (2010). ConSurf 2010: calculating evolutionary conservation in sequence and structure of proteins and nucleic acids. Nucleic Acids Research 38 (Web Server issue), W529-W533. doi: 10.1093/nar/gkq399.

Avila, J., Wandosell, F. and Hernández, F. (2010). Role of glycogen synthase kinase-3 in Alzheimer's disease pathogenesis and glycogen synthase kinase-3 inhibitors. Expert Review of Neurotherapeutics 10, 703-710. doi: 10.1586/ern.10.40.

Bertrand, J. A., Thieffine, S., Vulpetti, A., Cristiani, C., Valsasina, B., Knapp, S., Kalisz, H. M. and Flocco, M. (2003). Structural characterization of the GSK-3 $\beta$ active site using selective and non-selective ATPmimetic inhibitors. Fournal of Molecular Biology 333, 393-407. doi: 10.1016/j.jmb.2003.08.031.

Bhat, R., Xue, Y., Berg, S., Hellberg, S., Ormö, M., Nilsson, Y., Radesäter, A.-C., Jerning, J., Markgren, P.-O., Borgregård, T., Nylöf, M., Giménez-Cassina, A., Hernández, F., Lucas, J. J. Díaz-Nido, J. and Avila, J. (2003). Structural insights and biological effects of glycogen synthase kinase 3-specific inhibitor AR-A014418. The Fournal of Biological Chemistry 278, 45937-45945. doi: 10.1074/jbc. M306268200.

Canduri, F., Perez, P. C., Caceres, R. A. and de Azevedo, W. F. Jr. (2007). Protein kinases as targets for antiparasitic chemotherapy drugs. Current Drug Targets 8, 389-398.

Chellan, G., Shivaprakash, S., Ramaiyar, S. K., Varma, A. K., Varma, N., Sukumaran, M. T., Vasukutty, J. R., Bal, A. and Kumar, H. (2010). Spectrum and Prevalence of Fungi Infecting Deep Tissues of Lower-Limb Wounds in Patients with Type 2 Diabetes. Fournal of Clinical Microbiology 48, 2097-2102. doi: 10.1128/JCM.02035-09.

Dajani, R., Fraser, E., Roe, S. M., Young, N., Good, V., Dale, T. C. and Pearl, L.H. (2001). Crystal structure of glycogen synthase kinase $3 \beta$ : structural basis for phosphate-primed substrate specificity and autoinhibition. Cell 105, 721-732. doi: 10.1016/S0092-8674(01)00374-9.

Dajani, R., Fraser, E., Roe, S. M., Yeo, M., Good, V. M., Thompson, V., Dale, T. C. and Pearl, L. H. (2003). Structural basis for recruitment of glycogen synthase kinase $3 \beta$ to the axin-APC scaffold complex. The EMBO Fournal 22, 494-501. doi: 10.1093/emboj/cdg068.

Droucheau, E., Primot, A., Thomas, V., Mattei, D., Knockaert, M., Richardson, C., Sallicandro, P., Alano, P., Jafarshad, A., Baratte, B., Kunick, C., Parzy, D., Pearl, L., Doerig, C. and Meijer, L. (2004). Plasmodium falciparum glycogen synthase kinase-3: molecular model, expression, intracellular localisation and selective inhibitors. Biochimica et Biophysica Acta 1607, 181-196. doi: 10.1016/j.bbapap.2003.11.023. 
Dugo, L., Collin, M. and Thiemermann, C. (2007). Glycogen synthase kinase $3 \beta$ as a target for the therapy of shock and inflammation. Shock 27, 113-123. doi: 10.1097/01.shk.0000238059.23837.68.

Embi, N., Rylatt, D. B. and Cohen, P. (1980). Glycogen synthase kinase-3 from rabbit skeletal muscle. European fournal of Biochemistry 107, 519-527. doi: 10.1111/j.1432-1033.1980.tb06059.x.

Fabres, A., Pinto de Andrade, C., Guizzo, M., Sorgine, M. H.F., Paiva-Silva, G. D. O., Masuda, A., Da Silva Vaz, I. Jr. and Logullo, C. (2010). Effect of GSK-3 activity, enzymatic inhibition and gene silencing by RNAi on tick oviposition and egg hatching. Parasitology 137, 1537-1546. doi: $10.1017 /$ S0031182010000284.

Frame, S. and Zheleva, D. (2006). Targeting glycogen synthase kinase-3 in insulin signalling. Expert Opinion on Therapeutic Targets 10, 429-444. doi: $10.1517 / 14728222.10 .3 .429$.

Gamo, F.-J., Sanz, L. M., Vidal, J., de Cozar, C., Alvarez, E., Lavandera, J.-L., Vanderwall, D. E., Green, D. V.S., Kumar, V., Hasan, S., Brown, J. R., Peishoff, C.E., Cardon, L. R. and GarciaBustos, J. F. (2010). Thousands of chemical starting points for antimalarial lead identification. Nature, London 465, 305-310. doi: 10.1038/nature09107. Glaser, F., Pupko, T., Paz, I., Bell, R. E., Bechor, D., Martz, E. and Ben-Tal, N. (2003). ConSurf: Identification of functional regions in proteins by surface-mapping of phylogenetic information. Bioinformatics 19, 163-164. doi: 10.1093/bioinformatics/19.1.163.

Henriksen, E. J. and Dokken, B. B. (2006). Role of glycogen synthase kinase-3 in insulin resistance and type 2 diabetes. Current Drug Targets 7 , 1435-1441.

Hoskins, R. A., Carlson, J. W., Kennedy, C., Acevedo, D., Evans-Holm, M., Frise, E., Wan, K. H., Park, S., Mendez-Lago, M., Rossi, F., Villasante, A., Dimitri, P., Karpen, G. H. and Celniker, S. E. (2007). Sequence finishing and mapping of Drosophila melanogaster heterochromatin. Science 316, 1625-1628. doi: 10.1126/science.1139816.

Ibrahim, M. A., Shilabin, A. G., Prasanna, S., Jacob, M., Khan, S. I., Doerksen, R. J. and Hamann, M. T. (2008). 2-N-methyl modifications and SAR studies of manzamine A. Bioorganic and Medicinal Chemistry 16, 6702-6706. doi: 10.1016/j.bmc.2008.05.079.

Kassir, Y., Rubin-Bejerano, I. and Mandel-Gutfreund, Y. (2006). The Saccharomyces cerevisiae GSK- $3 \beta$ homologs. Current Drug Targets 7 , 1455-1465.

Kruggel, A. and Lemcke, T. (2009a). Comparative investigation of the ATP-binding site of human and plasmodial glycogen synthase kinase-3. QSAR and Combinatorial Science 28, 885-890. doi: 10.1002/ qsar.200860193.

Kruggel, A. and Lemcke, T. (2009b). Generation and evaluation of a homology model of PfGSK-3. Archiv der Pharmazie-Chemistry in Life Sciences 342, 327-332. doi: 10.1002/ardp.200800158.

Kurosu, M. and Begari, E. (2010). Bacterial protein kinase inhibitors. Drug Development Research 71, 168-187. doi: 10.1002/ddr.20362.

Landau, M., Mayrose, I., Rosenberg, Y., Glaser, F., Martz, E., Pupko, T. and Ben-Tal, N. (2005). ConSurf 2005: the projection of evolutionary conservation scores of residues on protein structures. Nucleic Acids Research 33 (Web Server issue), W299-W302. doi: 10.1093/nar/ gki370.

Larkin, M. A., Blackshields, G., Brown, N. P., Chenna, R., McGettigan, P. A., McWilliam, H., Valentin, F., Wallace, I. M., Wilm, A., Lopez, R., Thompson, J. D., Gibson, T. J. and Higgins, D. G. (2007). Clustal W and Clustal X version 2.0. Bioinformatics 23, 2947-2948. doi: 10.1093/bioinformatics/btm404.

Laskowski, R. A., MacArthur, M. W., Moss, D. S. and Thornton, J. M. (1993). PROCHECK - a program to check the stereochemical quality of protein structures. Fournal of Applied Crystallography 26, 283-291. doi: 10.1107/S0021889892009944.

Liang, M.-H. and Chuang, D.-M. (2006). Differential Roles of Glycogen Synthase Kinase-3 Isoforms in the Regulation of Transcriptional Activation. The Fournal of Biological Chemistry 281, 30479-30484. doi: 10.1074/jbc.M607468200

Liotta, F. and Siekierka, J. J. (2010). Apicomplexa, trypanosoma and parasitic nematode protein kinases as antiparasitic therapeutic targets. Current Opinion in Investigational Drugs 11, 147-156.

Lochhead, P. A., Kinstrie, R., Sibbet, G., Rawjee, T., Morrice, N. and Cleghon, V. (2006). A chaperone-dependent GSK3 $\beta$ transitional intermediate mediates activation-loop autophosphorylation. Molecular Cell 24, 627-633. doi: 10.1016/j.molcel.2006.10.009.

Logullo, C., Witola, W. H., Andrade, C., Abreu, L., Gomes, J., da Silva Vaz, I. Jr., Imamura, S., Konnai, S., Ohashi, K. and Onuma, M. (2009). Expression and activity of glycogen synthase kinase during vitellogenesis and embryogenesis of Rhipicephalus (Boophilus) microplus. Veterinary Parasitology 161, 261-269. doi: 10.1016/j.vetpar. 2009.01.029.
Martinez, A., Alonso, M., Castro, A., Dorronsoro, I., Gelpí, J.L., Luque, F. J., Pérez, C. and Moreno, F. J. (2005). SAR and 3D-QSAR studies on thiadiazolidinone derivatives: exploration of structural requirements for glycogen synthase kinase 3 inhibitors. Fournal of Medicinal Chemistry 48, 7103-7112. doi: 10.1021/jm040895g.

Meijer, L., Skaltsounis, A.-L. L., Magiatis, P., Polychronopoulos, P., Knockaert, M., Leost, M., Ryan, X. P., Vonica, C. A. A., Brivanlou, A., Dajani, R., Crovace, C., Tarricone, C., Musacchio, A., Roe, S. M. Pearl, L. and Greengard, P. (2003). GSK-3-selective inhibitors derived from Tyrian purple indirubins. Chemistry and Biology 10, 1255-1266. doi:10.1016/j.chembiol.2003.11.010.

Nicholas, K. B., Nicholas, H. B. Jr. and Deerfield II, D. W. (1997). GeneDoc: analysis and visualization of genetic variation. EMBnet.news 4, 14-17.

Ojo, K. K., Gillespie, J.R., Riechers, A. J., Napuli, A. J., Verlinde, C. L. M. J., Buckner, F. S., Gelb, M. H., Domostoj, M. M., Wells, S. J., Scheer, A., Wells, T. N. C. and Van Voorhis, W. C. (2008). Glycogen synthase kinase 3 is a potential drug target for african trypanosomiasis therapy. Antimicrobial Agents and Chemotherapy 52, 3710-3717. doi:10.1128/AAC.00364-08.

Ougolkov, A.V. and Billadeau, D.D. (2006). Targeting GSK-3: a promising approach for cancer therapy? Future Oncology 2, 91-100. doi: 10.2217/14796694.2.191.

Patel, S. and Woodgett, J. (2008). Glycogen syntase kinase-3 and cancer: good cop, bad cop? Cancer Cell 14, 351-353. doi: 10.1016/j.ccr.2008.10.013. Peng, J., Kudrimoti, S., Prasanna, S., Odde, S., Doerksen, R. J., Pennaka, H. K., Choo, Y.-M., Rao, K. V., Tekwani, B. L., Madgula, V., Khan, S.I., Wang, B., Mayer, A.M.S., Jacob, M. R., Tu, L.C., Gertsch, J. and Hamann, M. T. (2010). Structure-activity relationship and mechanism of action studies of manzamine analogues for the control of neuroinflammation and cerebral infections. Fournal of Medicinal Chemistry 53, 61-76. doi: 10.1021/jm900672t.

Qin, C., Tang, J. and Kim, K. (1998). Cloning and in vitro expression of TPK3, a Toxoplasma gondii homologue of shaggy/glycogen synthase kinase3 kinases. Molecular and Biochemical Parasitology 93, 278-283. doi: 10.1016/ S0166-6851(98)00042-5.

Rayasam, G.V., Tulasi, V.K., Sodhi, R., Davis, J. A. and Ray, A. (2009). Glycogen synthase kinase 3: more than a namesake. British fournal of Pharmacology 156, 885-898. doi: 10.1111/j.1476-5381.2008.00085.x.

Šali, A. and Blundell, T. L. (1993). Comparative protein modelling by satisfaction of spatial restraints. Fournal of Molecular Biology 234, 779-815. doi: 10.1006/jmbi.1993.1626.

Sippl, M. J. (1993). Recognition of errors in three-dimensional structures of proteins. PROTEINS: Structure, Function and Genetics 17, 355-362. doi: 10.1002/prot.340170404

Tamura, K., Dudley, J., Nei, M. and Kumar, S. (2007). MEGA4: Molecular Evolutionary Genetics Analysis (MEGA) software version 4.0. Molecular Biology and Evolution 24, 1596-1599. doi:10.1093/molbev/ msm092.

Thornton, T. M., Pedraza-Alva, G., Deng, B., Wood, C.D., Aronshtam, A., Clements, J. L., Sabio, G., Davis, R. J., Matthews, D. E., Doble, B. and Rincon, M. (2008). Phosphorylation by p38 MAPK as an Alternative Pathway for GSK3 $\beta$ Inactivation. Science 320, 667-670. doi: 10.1126/science.1156037.

Wu, D. and Pan, W. (2009). GSK3: a multifaceted kinase in Wnt signaling. Trends in Biochemical Sciences 35, 161-168. doi: 10.1016/j.tibs.2009.10.002. Xiao, J.-F., Li, Z.-S., Sun, M., Zhang, Y. and Sun, C.-C. (2004) Homology modeling and molecular dynamics study of GSK3/SHAGGYlike kinase. Computational Biology and Chemistry 28, 179-188. doi: 10.1016/ j.compbiolchem.2004.02.003.

Xingi, E., Smirlis, D., Myrianthopoulos, V., Magiatis, P., Grant, K. M., Meijer, L., Mikros, E., Skaltsounis, A.-L. and Soteriadou, K. (2009). 6-Br-5methylindirubin-3'oxime (5-Me-6-BIO) targeting the leishmanial glycogen synthase kinase-3 (GSK-3) short form affects cell-cycle progression and induces apoptosis-like death: exploitation of GSK-3 for treating leishmaniasis. International fournal for Parasitology 39, 1289-1303. doi: 10.1016/j.ijpara.2009.04.005

Zhang, J., Yang, P. L. and Gray, N.S. (2009a). Targeting cancer with small molecule linase inhibitors. Nature Reviews Cancer 9, 28-39. doi: $10.1038 / \mathrm{nrc} 2559$.

Zhang, N., Jiang, Y., Zou, J., Yu, Q. and Zhao, W. (2009b). Structural basis for the complete loss of GSK $3 \beta$ catalytic activity due to R96 mutation investigated by molecular dynamics study. PROTEINS: Structure, Function and Bioinformatics 75, 671-681. doi: 10.1002/prot.22279.

Zuccotto, F., Ardini, E., Casale, E. and Angiolini, M. (2010). Through the "Gatekeeper Door": Exploiting the Active Kinase Conformation. Fournal of Medicinal Chemistry 53, 2681-2694. doi: $10.1021 / \mathrm{jm} 901443 \mathrm{~h}$ 